\title{
Féeries
}

Études sur le conte merveilleux, XVII ${ }^{\mathrm{e}} \mathrm{XIX} \mathrm{X}^{\mathrm{e}}$ siècle

4 | 2007

Le conte, la scène

\section{Annexe : Liste chronologique des pièces citées}

\section{Christelle Bahier-Porte}

\section{(2) OpenEdition}

\section{Journals}

Édition électronique

URL : http://journals.openedition.org/feeries/513

DOI : $10.4000 /$ feeries. 513

ISSN : 1957-7753

Éditeur

UGA Éditions/Université Grenoble Alpes

Édition imprimée

Date de publication : 1 octobre 2007

ISBN : 978-2-84310-101-4

ISSN : 1766-2842

\section{Référence électronique}

Christelle Bahier-Porte, « Annexe : Liste chronologique des pièces citées », Féeries [En ligne], 4 | 2007, mis en ligne le 03 novembre 2008, consulté le 15 septembre 2020. URL : http:// journals.openedition.org/feeries/513

Ce document a été généré automatiquement le 15 septembre 2020.

(c) Féeries 


\title{
Annexe : Liste chronologique des pièces citées
}

\author{
Christelle Bahier-Porte
}

1 Cette liste a été établie à partir des études consacrées, dans ce numéro, au rapport entre le conte et le théâtre. Sa seule ambition est de donner au lecteur un aperçu de l'abondante production féerique des théâtres de la fin du XVII ${ }^{\mathrm{e}}$ au début du XIX ${ }^{\mathrm{e}}$ siècle. Nous avons choisi une liste chronologique conforme à la date de la première représentation (et non de la première édition) plutôt qu'une liste alphabétique afin de montrer l'évolution des deux genres au fil des siècles. Nous indiquons entre crochets le conte qui a servi de modèle dans les cas d'adaptations non transparentes. Qu'on nous permette un souhait à l'issue de ce numéro riche en découvertes : que cette liste soit complétée au gré des trouvailles de chacun*.

21641 L'Esprit folet, D'Ouville, Comédie-Française.

31650 Andromède, Corneille, tragédie à machines, Comédie-Française.

41656 Le Ballet de Psyché ou De la puissance de l'amour, Benserade, musique de Lully et Boësset, chorégraphie de Beauchamps, ballet, Théâtre de la Cour au Château du Louvre, dansé par le Roi.

51671 Psyché, tragédie ballet, Corneille, Molière, Quinault, musique de Lully.

61673 Cadmus et Hermione, Quinault et Lully, tragédie en musique, Académie royale de Musique.

71678 Les Forces de l'amour et de la magie, Allard et Vondrebeck, Foire Saint-Germain. Psyché, tragédie lyrique, Thomas Corneille, Fontenelle, musique de Lully, Académie royale de Musique.

81679 La Devineresse ou Les Faux Enchantements, Thomas Corneille et Donneau de Visée, Comédie-Française.

91697 Les Fées ou Les Contes de ma mère l'Oye, Dufresny [et Brugière de Barante], pièce donnée en société, et jouée par Dufresny et le comédien Biancolelli fils, puis reprise à la Comédie-Italienne. 

$\mathrm{M}^{\mathrm{me}}$ Durand, 1702]

Arlequin roi des ogres ou les Bottes de sept lieues, Lesage, Fuzelier, d'Orneval, Foire SaintGermain.

La Queue de vérité, Fuzelier, Lesage et d'Orneval, Foire Saint-Germain.

La Statue merveilleuse, Lesage, Fuzelier, d'Orneval, Foire Saint-Laurent, [« Histoire de Zeyn Alasnam et du roi des génies ", conte du tome VIII controversé des Mille et Une Nuits, 1708.]

1722 Le Jeune Vieillard, Lesage, Fuzelier, d'Orneval, Foire Saint-Laurent, [« Histoire des deux frères génies, Adis et Dahy ", conte des Mille et Un Jours, 1710-1712]

La Foire des fées, Lesage, Fuzelier, D’Orneval, Foire Saint-Laurent, [«Les Souhaits ridicules », « La Belle au Bois dormant », Perrault, 1697]

1729 La Princesse de la Chine, Lesage, Fuzelier, d'Orneval, Foire Saint-Laurent, [« Histoire du prince Calaf et de la princesse de la Chine », conte des Mille et Un Jours, 1710-1712]

1730 La Pantoufle, Marignier, Foire saint-Germain, [Cendrillon, Perrault, 1697]

La Sylphide, Biancolelli et Romagnesi, Comédie-Italienne. [Le Sylphe (1730) de Crébillon sert de prétexte]

1731 Roger roi de Sicile, Lesage, Fuzelier, d'Orneval, [« Histoire du roi Hormoz, surnommé le roi sans chagrin ", conte des Mille et Un Jours, 1710-1712]

Le Prince de Noisy, M. d'Aigbere, Comédie-Française. [Le Bélier, Hamilton]

1732 L'Épreuve des fées, Fuzelier, Foire Saint-Laurent.

21

1733 Hippolyte et Aricie, Pellegrin et Rameau, tragédie lyrique, Académie Royale de Musique ["Cendrillon », Perrault, 1697]

1734 La Fée Marotte, d'Allainval, Foire Saint-Laurent.

Île des fées ou Le Géant aux marionnettes, anonyme, Foire Saint-Laurent.

Le Conte de fées, Romagnesi et Luigi Riccoboni, Comédie-Italienne.

Margéon et Katifé, Boissy, Opéra-Comique [Gueullette, Les Sultanes de Guzarate, 1732]

1736 La Fée bienfaisante, Pannard, Foire Saint-Laurent.

Les Fées, Romagnesi et Procope-Couteaux, Comédie-Italienne. ["Riquet à la Houppe », Perrault, 1697]

1737 La Fée Brochure, Carolet, Foire Saint-Laurent.

Polichinelle roi des fées, anonyme, Foire Saint-Germain. 


\section{comique, Foire Saint-Laurent.}

Blaise le savetier, Sedaine, musique de Philidor, opéra-comique, Théâtre de Cour de Fontainebleau, puis repris à la Foire Saint-Germain, puis à la Comédie-Italienne [librement inspiré de La Fontaine]. 
1761 Soliman second ou Les trois sultanes, Favart, musique de Gilbert, Comédie-Italienne. [Soliman II, anecdote turque, Marmontel, Contes moraux publiés en 1761].

1762 Armide, Laujon, Riccoboni fils, parodie, Comédie-Italienne.

Annette et Lubin, Favart et Voisenon, Comédie-Italienne.

Annette et Lubin, Marmontel, Théâtres de société, théâtre privé du Château de Choisy. Heureusement, Rochon de Chabannes, Comédie-Française.

1763 Le Bûcheron ou les Trois Souhaits, Jean-François Guichard et Philidor, ComédieItalienne.

1764 Le Sorcier, Poinsinet et Philidor, Comédie-Italienne.

L'Anneau perdu et retrouvé, Sedaine, musique de Chardin et de La Borde, Opéra-comique, Comédie-Italienne en 1788.

1765 La Fée Urgèle ou Ce qui plaît aux dames, Favart et Voisenon, Comédie-Italienne. [Ce qui plait aux dames, Voltaire, 1764].

Isabelle et Gertrude ou le sylphes supposés, Favart, musique de A.B. Blaise, ComédieItalienne. [L'éducation d'une fille, Voltaire, 1763].

1766 La Barbe bleue, Delautel, « tragédie amphigourique », Théâtre de Nicolet.

1767 L'Île sonnante, Collé, Monsigny, Théâtre de société puis reprise à la ComédieItalienne.

1768 La Sorcière par hasard, Nicolas-Étienne Framery, Théâtre de société.

Le Huron, Marmontel, Comédie-Italienne [L'Ingénu, Voltaire, 1767]

Les Sabots, Sedaine et Cazotte, musique de Duni, opéra-comique, Comédie-Italienne, repris très largement en Europe et jusqu'à Moscou [d'après Perrault].

1768/1769 Le Petit Poucet, Carmontelle, Théâtres de société.

1769 Le Bouquet enchanté, Théâtre de Nicolet.

Lucile, Marmontel, Grétry, Comédie-Italienne.

1770 L'Amitié à l'épreuve, Favart, Voisenon Grétry, Fontainebleau puis reprise à la Comédie-Italienne [d'après un conte moral de Marmontel].

La Belle au bois dormant, Arnould, Ambigu Comique.

La Tour enchantée, Joliveau, ballet figuré.

Le Chat botté, Nougaret, Ambigu Comique.

1771 Zémire et Azor, Marmontel, musique de Grétry, comédie ballet. [«La Belle et la Bête ", $\mathrm{M}^{\mathrm{me}}$ Leprince de Beaumont, 1756]

1771/1772 Le Petit Poucet, Renout, Ambigu Comique.

Le Faucon, Sedaine, Château de Fontainebleau puis repris au Grand Théatre de la Monnaie de Bruxelles [d'après la nouvelle de La Fontaine].

1772 Le Bouquet enchanté, Carmontelle, Théâtres de société.

1773 Le Magnifique, Sedaine, Château de Versailles, puis repris à la Comédie-Française [d'après La Fontaine].

La Belle Arsène, comédie-féeries, Favart, musique de Monsigny, Théâtre de Fontainebleau, puis Comédie-Italienne en 1775. [La Bégueule, conte moral, Voltaire, 1772].

1774 Le Petit Chaperon rouge, Mension, Ambigu Comique,

1776 Voisenon, Fleur d'Épine, Comédie-Italienne [d'après le conte éponyme d'Hamilton]. 
601778 (édité en 1779) La Belle et la Bête, $\mathrm{M}^{\mathrm{me}}$ de Genlis, Théâtres de société, théâtre privé d'éducation [« La Belle et la Bête », $\mathrm{M}^{\mathrm{me}}$ Leprince de Beaumont, 1756].

L'île heureuse, $\mathrm{M}^{\mathrm{me}}$ de Genlis, Théâtres de société, théâtre privé d'éducation.

1778 Le Sylphe ou le Mari comme il y en a peu, Martin de Choisy, Théâtre de Montpellier.

1779 Le Bouquet de la fée bienfaisante, Théâtre des Grands Danseurs.

La Barbe bleue, pantomime, Ambigu Comique.

Les Amours de la fée Carabosse ou le Bouquet enchanté, Théâtre des Grands Danseurs.

Aucassin et Nicolette ou Les Mœurs du bon vieux temps, Sedaine, musique de Grétry, Château de Versailles puis repris à la Comédie-Italienne [d'après un fabliau du XIII ${ }^{\mathrm{e}}$ siècle].

1780 La Barbe bleue, Théâtre des élèves de l'Opéra.

641782 La Barbe bleue, Poultier d'Elmotte, Théâtre de Lunéville.

651783 La Belle au bois dormant, pantomime, Lyon.

661785 Cendrillon, Maillé de Marencourt, Théâtre de Seraphin,

671789 Raoul Barbe Bleue, Sedaine, musique de Grétry, Comédie-Italienne.

\section{NOTES}

*. Un grand merci à Martial Poirson pour sa relecture. 